\title{
Effects of natural free radical scavengers on peripheral nerve and neurovascular function in diabetic rats
}

\author{
M.A. Cotter, A. Love, M.J. Watt, N. E. Cameron, K. C. Dines \\ Department of Biomedical Sciences, University of Aberdeen, Aberdeen, Scotland
}

Summary Increased generation of reactive oxygen species, coupled with impaired endogenous scavenging mechanisms, plays a prominent role in the aetiology of neurovascular abnormalities in experimental diabetes mellitus. We examined the efficacy of the natural anti-oxidants vitamins $\mathrm{C}, \mathrm{E}$ and $\beta$-carotene in preventing nerve conduction and nutritive blood flow deficits in streptozotocin-diabetic rats. One month of diabetes caused a $19.1 \%$ reduction in sciatic motor conduction velocity $(p<0.001)$. This was approximately prevented $80-90 \%$ by high-dose $\left(1000 \mathrm{mg} \cdot \mathrm{kg}^{-1} \cdot \mathrm{day}^{-1}\right)$ vitamin $\mathrm{E}$ and $\beta$-carotene treatments $(p<0.001)$. Vitamin $C$ had lesser effects; the maximum protection found for motor conduction velocity was $36 \%$ using a dose of $150 \mathrm{mg}$. $\mathrm{kg}^{-1} \cdot \mathrm{day}^{-1} \quad(p<0.001)$. High dose $(500 \mathrm{mg}$. $\mathrm{kg}^{-1} \cdot$ day $^{-1}$ ) vitamin $\mathrm{C}$ had a lesser effect on conduction than intermediate doses. Joint vitamin $\mathrm{C}$ and lower dose $\left(500 \mathrm{mg} \cdot \mathrm{kg}^{-1} \cdot \mathrm{day}^{-1}\right)$ vitamin $\mathrm{E}$ treatment had a predominantly additive preventive effect against nerve dysfunction. Resistance to hypoxic conduction failure for sciatic nerve in vitro was markedly increased by diabetes and this remained relatively unaffected by treatment. Sciatic nutritive endoneurial blood flow, measured using microelectrode polarography and hydrogen clearance, was reduced $46.1 \%$ by 1 month of diabetes $(p<0.001)$. This was prevented to the extent of $87 \%, 36 \%$ and $98 \%$ by vitamins $\mathrm{E}, \mathrm{C}$ and $\beta$-carotene, respectively $(p<0.01)$. These data emphasize the role of oxidative stress in the development of early neurovascular changes in experimental diabetes and show that naturally available scavengers have a neuroprotective action. [Diabetologia (1995) 38: 1285-1294]

Key words Neuropathy, nerve conduction, endoneurial blood flow, ischaemia, oxidative stress, vitamin C, vitamin $\mathrm{E}, \beta$-carotene, anti-oxidant, vascular endothelium, diabetic rat.
Increased activity of reactive oxygen species (ROS), coupled with a weakening of natural cellular protection mechanisms contributes to vascular dysfunction in diabetes mellitus [1-4]. In normotensive subjects without evidence of microvascular complications, acute intravenous anti-oxidant administration caused a much greater hypotensive effect in diabetic than in non-diabetic individuals [5], suggesting a

Received: 31 March 1995 and in revised form: 16 June 1995

Corresponding author: Dr. N. E. Cameron, Department of Biomedical Sciences, University of Aberdeen, Marischal College, Aberdeen AB9 1AS, UK

Abbreviations: NCV, Nerve conduction velocity; NO, nitric oxide; ROS, reactive oxygen species. widespread involvement of ROS-related mechanisms in the disrupted control of tone in the major vascular beds. A likely action of superoxide anions is to neutralize nitric oxide (NO), which causes a characteristic deficit in endothelium-dependent relaxation [6-10]. Recently, anti-oxidant treatment studies have led to the view that free radical activity is involved in the reduction in nutritive blood flow that causes peripheral nerve hypoxia and dysfunction in experimental models of diabetes [11-13].

The main dietary sources of ROS scavengers include vitamins $\mathrm{C}$ (ascorbate) and $\mathrm{E}$ (D- $\alpha$-tocopherol) and the precursor of vitamin $A, \beta$-carotene. Vitamin $C$ content is depressed by diabetes, with a concomitant increase in dehydroascorbate [14-17]. 
Restriction of dietary vitamin $\mathrm{E}$ intake causes neuropathic changes in non-diabetic rats and exacerbates the nerve conduction velocity (NCV) deficit in diabetic rats [15]. Vitamin $\mathrm{E}$ is a lipophilic anti-oxidant that scavenges the most highly reactive and damaging of the ROS, the hydroxyl radical, and can stem the chain reaction of polyunsaturated fatty acidperoxidation in membranes [18]. This action may be aided by vitamin $C$, which can regenerate $\alpha$-tocopherol from the tocopheroxyl radical, at least in vitro $[19]$. The primary action of $\beta$-carotene against ROS is to quench excited singlet oxygen species [18]. The aim of this investigation was to assess the extent of protection against NCV and nutritive endoneurial blood flow defects afforded by vitamins $C, E$, and $\beta$ carotene in streptozotocin-diabetic rats.

\section{Materials and methods}

The experiments were performed in accordance with regulations specified in the United Kingdom "Animal Procedures Act, 1986" and the National Institutes of Health "Principles of Laboratory Animal Care, 1985 revised version".

Diabetes induction and experimental design. Male SpragueDawley rats (Aberdeen University breeding colony), 19 weeks old at the start of the study were used. Non-diabetic. animals acted as onset controls. Diabetes, induced by intraperitoneal administration of streptozotocin (Zeneca Pharmaceuticals, Macclesfield, Cheshire, UK) at $40-45 \mathrm{mg} \cdot \mathrm{kg}^{-1}$ freshly dissolved in sterile $0.9 \% \mathrm{NaCl}$ solution, was verified $24 \mathrm{~h}$ later by estimating hyperglycaemia and glycosuria (Visidex II and Diastix; Ames, Slough, UK). Diabetic rats were tested weekly and weighed daily. Animals were rejected if the plasma glucose concentration was more than $20 \mathrm{mmol} \cdot \mathrm{l}^{-1}$ or if body weight consistently increased over 3 days. Samples were taken from the tail vein or carotid artery after final experiments for plasma glucose determination (GOD-Perid method; Boehringer Mannheim, Mannheim, Germany).

The main experimental design involved treatment for 1 month, 2 days after diabetes was verified. Vitamin $\mathbf{C}$ ( $\mathbf{L}^{-}$ ascorbic acid; Sigma, Poole, Dorset, UK) was given in the drinking water such that the dose was approximately 150 $\mathrm{mg} \cdot \mathrm{kg}^{-1} \cdot \mathrm{day}^{-1}$. This dose was found to be maximally effective in a preliminary study which examined the dose-response relationship (treatment range $5-500 \mathrm{mg} \cdot \mathrm{kg}^{-1} \cdot$ day $^{-1}$ ) for motor and sensory NCV using a reversal paradigm of 2 weeks' treatment following 6 weeks of untreated diabetes. Vitamin $\mathrm{E}$ (mixed isomers approximately $68 \% \mathrm{D}-, 32 \% \mathrm{~L}$ - $\alpha$-tocopherol, from vegetable oil; Sigma) and $\beta$-carotene (Sigma) were given as dietary supplements, the dose being approximately 1000 $\mathrm{mg} \cdot \mathrm{kg}^{-1} \cdot$ day $^{-1}$. Further experiments studied the interaction between vitamin $C\left(150 \mathrm{mg} \cdot \mathrm{kg}^{-1} \cdot \mathrm{day}^{-1}\right)$ and vitamin $\mathrm{E}(500$ $\mathrm{mg} \cdot \mathrm{kg}^{-1} \cdot$ day $^{-1}$ ) co-treatment on $\mathrm{NCV}$. The vitamin $\mathrm{E}$ doseresponse relationship $\left(100-1000 \mathrm{mg} \cdot \mathrm{kg}^{-1} \cdot \mathrm{day}^{-1}\right)$ was also determined for prevention of motor NCV deficits.

Nerve conduction velocity and resistance to hypoxic conduction failure. In final experiments $\left(1.0-1.5 \mathrm{~g} \cdot \mathrm{kg}^{-1}\right.$ urethane or $50-$ $100 \mathrm{mg} \cdot \mathrm{kg}^{-1}$ thiobutabarbital anaesthesia i. p.), NCV was measured in vivo between the sciatic notch and the knee for sciatic motor branches supplying tibialis anterior (peroneal division) and gastrocnemius (tibial division) muscles for study 1 or tibia- lis anterior muscle alone for study 2 . Sensory NCV was measured in the saphenous nerve between the groin and ankle. Rectal and nerve temperatures were monitored, and regulated between 36.5 and $37.5^{\circ} \mathrm{C}$. Methods have previously been described in detail [20].

In study 1 , sciatic nerve resistance to hypoxic conduction failure was measured in vitro for nerves from the contralateral leg as previously described [21]. The sciatic trunk was removed and mounted on bipolar stimulating (proximal end) and recording (distal end) electrodes in a chamber containing Krebs-Ringer solution at $35^{\circ} \mathrm{C}$, with $5.5 \mathrm{mmol} \cdot 1^{-1}$ glucose for nerves from non-diabetic, and $40 \mathrm{mmol} \cdot 1^{-1}$ glucose for the diabetic rats. Bathing fluid was gassed with $95 \% \mathrm{O}_{2} 5 \% \mathrm{CO}_{2}$. Nerves were equilibrated for $30 \mathrm{~min}$, then the chamber was refilled with mineral oil pre-gassed for $1 \mathrm{~h}$ with $100 \% \mathrm{~N}_{2}$. Nerves were stimulated with just supramaximal pulses $(1 \mathrm{~Hz}, 0.05 \mathrm{~ms}$ width, $10 \mathrm{~mA}$ ) and compound action potential amplitude was monitored at 2-min intervals until it fell below $10 \%$ of its initial value.

Sciatic endoneurial blood flow. Rats were anaesthetized with thiobutabarbital (50-100 $\mathrm{mg} \cdot \mathrm{kg}^{-1}$ i. p.). The trachea was cannulated for artificial ventilation and a carotid cannula was used to monitor mean systemic blood pressure. Sciatic endoneurial blood flow was measured using microelectrode polarography and hydrogen clearance as previously described $[11,22]$. The hydrogen polarography method was chosen because it has been widely used to measure flow in a variety of tissues over the past 40 years [reviewed in 23, 24]. It has the advantage of permitting the measurement of nutritive (capillary) endoneurial blood flow which is crucial for neuronal function $[6,24]$. The flow reductions in nerves of untreated diabetic rats measured by this method are in qualitative agreement with other invasive and non-invasive techniques including clearance of electrolytically produced hydrogen, [14C]butanol or [14C]iodoantipyrine accumulation, [14C]iodoantipyrine autoradiography, and laser-Doppler flowmetry [reviewed in 6, 24]. One group, using a microsphere technique, has reported increased entrapment by vasa nervorum in diabetic rats, which was interpreted as increased blood flow [25]. However, this interpretation is only valid if the differences between diabetic and non-diabetic vasculature solely relate to flow, which is not the case [6]. In addition, the catch of microspheres by a small tissue (i. e. nerve tissue) is too low for accurate measurement [26] which probably accounts for a fivefold difference in reported putative resting nerve flow values between studies using this method in non-diabetic rats $[25,27]$; a level of variability that far exceeds the maximum physiological capacity to increase nerve blood flow above the resting value [24]. Thus, hydrogen clearance measurements in rats are likely to reflect accurately the state of endoneurial capillary perfusion and are, therefore, suitable for comparison with measures of nerve function.

Briefly, core temperature of the rat was monitored and regulated between 37 and $38^{\circ} \mathrm{C}$, using a rectal probe and radiant heat. The skin around the sciatic nerve incision was sutured to a metal ring and used to form a pool which was filled with mineral oil at $37^{\circ} \mathrm{C}$ to a depth of at least $1 \mathrm{~cm}$ to minimize gas diffusion. Rats were given neuromuscular blockade using D-tubocurarine (Sigma; $2 \mathrm{mg} \cdot \mathrm{kg}^{-1}$ via the carotid cannula) and artificially ventilated. The level of anaesthesia was monitored by observing any reaction of blood pressure to manipulation, and supplementary anaesthetic was given as necessary. A glass-insulated platinum microelectrode (tip diameter 2-8 $\mu \mathrm{m}, 45^{\circ}$ bevel) was inserted into the middle portion of the sciatic nerve, above its trifurcation, and polarized at $0.25 \mathrm{~V}$ with respect to a subcutaneous reference electrode. $\mathrm{H}_{2}(10 \%)$ was ad- 
Table 1. Body weights and plasma glucose concentrations for the non-diabetic, diabetic and treated diabetic rats used in this investigation

\begin{tabular}{|c|c|c|c|c|}
\hline & \multirow[b]{2}{*}{$n$} & \multicolumn{2}{|c|}{ Body weight (g) } & \multirow{2}{*}{$\begin{array}{l}\text { Plasma } \\
\text { glucose } \\
\left(\mathrm{mmol} \cdot \mathrm{l}^{-1}\right)\end{array}$} \\
\hline & & Start & End & \\
\hline Non-diabetic & 20 & $451 \pm 8$ & $\cdot$ & $8.5 \pm 0.4$ \\
\hline 1 month diabetic & 20 & $463 \pm 4$ & $363 \pm 7$ & $42.2 \pm 1.5$ \\
\hline $\begin{array}{l}1 \text { month diabetic } \\
+ \text { vitamin } \mathrm{C}\end{array}$ & 21 & $470 \pm 6$ & $379 \pm 8$ & $40.6 \pm 1.2$ \\
\hline $\begin{array}{l}1 \text { month diabetic } \\
+ \text { vitamin } E\end{array}$ & 26 & $458 \pm 7$ & $365 \pm 6$ & $44.9 \pm 1.5$ \\
\hline $\begin{array}{l}1 \text { month diabetic + } \\
\text { vitamins } C \text { and } E\end{array}$ & 9 & $467 \pm 6$ & $367 \pm 11$ & $39.0 \pm 1.6$ \\
\hline $\begin{array}{l}1 \text { month diabetic }+ \\
\beta \text {-carotene }\end{array}$ & 12 & $468 \pm 4$ & $372 \pm 7$ & $40.9 \pm 1.6$ \\
\hline $\begin{array}{l}1 \text { month diabetic }+ \\
\text { vitamin } \mathrm{E} \\
\text { (dose-response) }\end{array}$ & 32 & $460 \pm 7$ & $358 \pm 7$ & $45.1 \pm 1.3$ \\
\hline $\begin{array}{l}2 \text { month diabetic }+ \\
\text { vitamin C } \\
\text { (dose-response) }\end{array}$ & 36 & $452 \pm 5$ & $299 \pm 9$ & $43.3 \pm 1.2$ \\
\hline
\end{tabular}

Data are mean \pm SEM

ded to the inspired gas, the proportions of $\mathrm{O}_{2}$ and $\mathrm{N}_{2}$ being adjusted to 20 and $70 \%$, respectively. When the $\mathrm{H}_{2}$ current recorded by the electrode had stabilized $(15-40 \mathrm{~min})$, indicating equilibrium with arterial blood, the $\mathrm{H}_{2}$ supply was shut off and $\mathrm{N}_{2}$ delivery was increased appropriately. The $\mathrm{H}_{2}$ clearance curve was recorded up to baseline (25-75 min), the latter being defined as no systematic decline in electrode current over $5 \mathrm{~min}$. This procedure was then repeated at another nerve site. After the experiment, clearance curves were digitized and mono-exponential or bi-exponential curves were fitted to the data by computer using nonlinear regression software that employed the Marquardt algorithm and the least squares method for optimizing goodness-of-fit (Inplot; Graphpad, San Diego, Calif., USA). The slow exponent was taken to represent nutritive (capillary) flow $[22,23,28]$. Composite flow was calculated as the weighted sum of fast and slow exponents. Vascular conductance was determined by dividing flow by the mean arterial blood pressure during the recording period.

\section{Statistical analysis}

Unless otherwise stated, data were subjected to Bartlett's test for homogeneity of variances, and where necessary they were normalized by log transformation before being tested using one-way analysis of variance. When significance was attained $(p<0.05)$, between-group differences were established using the Student-Newman-Keuls multiple comparison test. All calculations were performed using a standard statistical software package (Instat; Graphpad). Data are expressed as mean \pm SEM.

\section{Results}

Body weights and plasma glucose values are given in Table 1 for all rats used in studies 1 and 2 . Body weight declined by approximately $20 \%$ after 1 month of diabetes, and this was not affected by
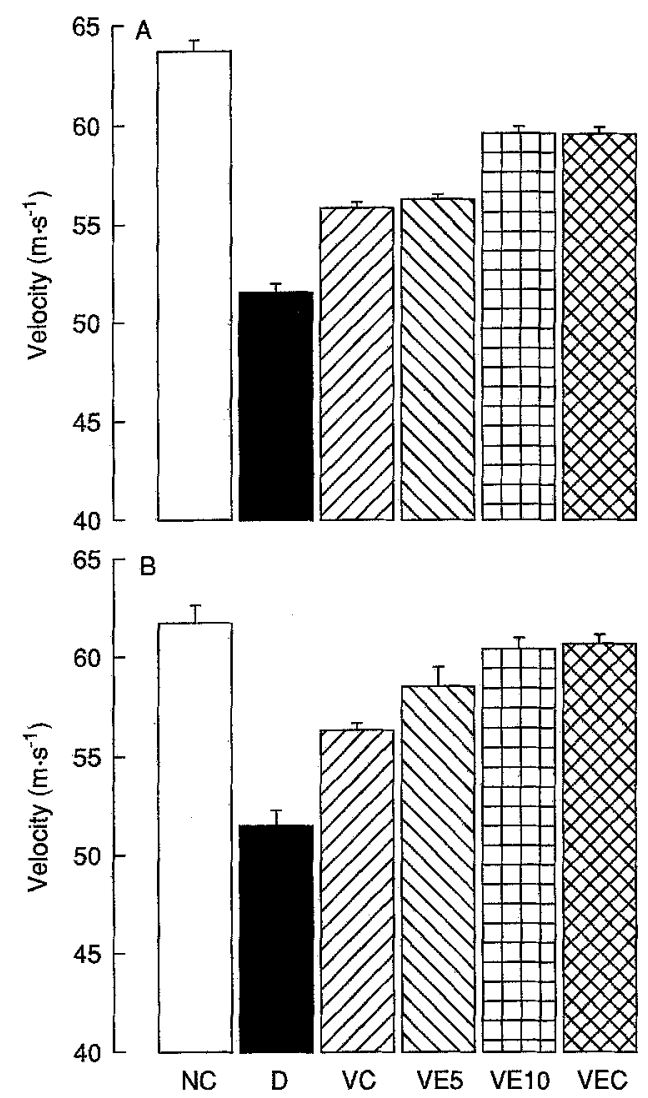

Fig.1A, B. Effects of vitamin $C$ and $E$ treatment, alone and in combination, on sciatic motor $(\mathbf{A})$ and saphenous sensory (B) conduction velocity in diabetic rats. NC, Non-diabetic control group $(n=10) ; \mathrm{D}, 1$ month diabetic group $(n=9)$; VC, 1 month diabetic group treated with vitamin $C$ (150 mg. $\mathrm{kg}^{-1} \cdot$ day $^{-1}$ ) from diabetes induction $(n=9)$; VE5, 1 month diabetic group treated with vitamin $E\left(500 \mathrm{mg} \cdot \mathrm{kg}^{-1} \cdot \mathrm{day}^{-1}\right)$ from induction $(n=8)$; VE10, 1 month diabetic group treated with vitamin $\mathrm{E}\left(1000 \mathrm{mg} \cdot \mathrm{kg}^{-1} \cdot\right.$ day $\left.^{-1}\right)$ from induction $(n=9)$; VEC, 1 month diabetic group treated with both vitamin C $\left(150 \mathrm{mg} \cdot \mathrm{kg}^{-1} \cdot \mathrm{day}^{-1}\right)$ and vitamin E $(500 \mathrm{mg}$. $\left.\mathrm{kg}^{-1} \cdot \mathrm{day}^{-1}\right)$ from induction $(n=9)$. Data are mean \pm SEM Statistics; motor conduction velocity, NC vs D, VC, VE5, VE10, VEC, $p<0.001$; D vs VC, VE5, VE10, VEC, $p<0.001$; VE5 vs VE10, $p<0.001$; VEC vs VC, VE5, $p<0.001$; sensory conduction velocity, $\mathrm{NC}$ vs $\mathrm{D}, \mathrm{VC}, p<0.001$; $\mathrm{NC}$ vs $\mathrm{VE} 5, p<0.01$; NC vs VE10, VEC NS; D vs VC, VE5, VE10, VEC, $p<0.001$; VE5 vs VE10, NS; VEC vs VC, $p<0.001$; VEC vs VE5, NS

treatment. Plasma glucose, elevated $4-5$-fold by diabetes, was also unaffected by treatment.

Study 1: effects of vitamins $C$ and $E$ on nerve conduction. One month of diabetes caused a $19.1 \pm 0.7 \%$ reduction $(p<0.001)$ in motor NCV (Fig. 1A). Vitamin $\mathrm{C}$, at a dose of $150 \mathrm{mg} \cdot \mathrm{kg}^{-1}$. day ${ }^{-1}$, reduced the development of the NCV deficit to $12.3 \pm 0.4 \%(p<0.001)$, although there remained a significant difference compared to non-diabetic control values $(p<0.001)$. Vita$\min \mathrm{E}\left(500 \mathrm{mg} \cdot \mathrm{kg}^{-1} \cdot \mathrm{day}^{-1}\right)$ approximately matched the effect of vitamin $\mathrm{C}(11.7 \pm 0.4 \%$ deficit, $p<0.001)$ whereas a higher dose $\left(1000 \mathrm{mg} \cdot \mathrm{kg}^{-1}\right.$. day $\left.{ }^{-1}\right)$ produced a more marked action, such that the motor 


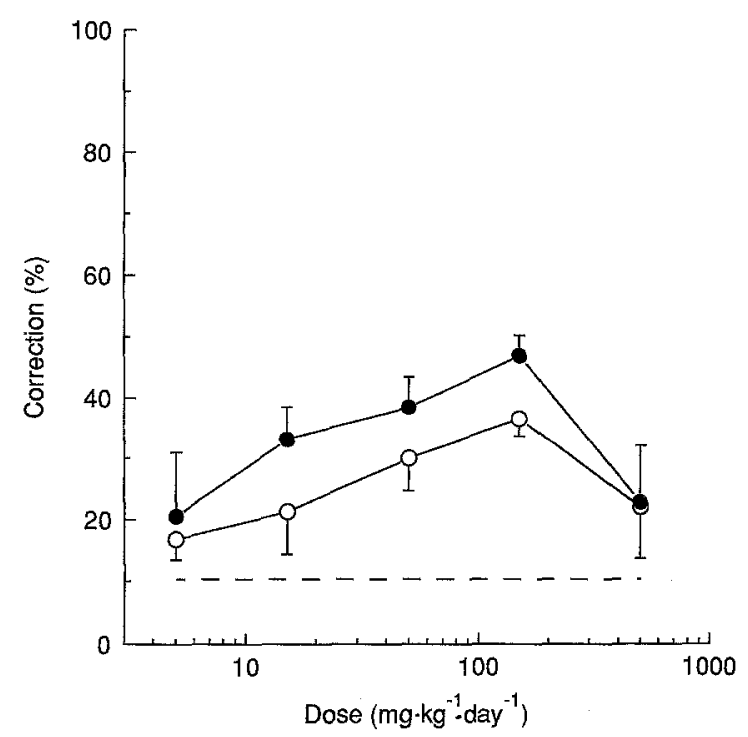

Fig. 2. Dose-response relationship for the correction of sciatic motor $(\bigcirc)$ and saphenous sensory (O) conduction velocity deficits by 2 weeks' vitamin C treatment following 6 weeks' untreated diabetes. Treatment doses were 5, 15, 50, 150 and $500 \mathrm{mg} \cdot \mathrm{kg}^{-1} \cdot$ day $^{-1}$ (group $n=6-10$ ). Horizontal dashed line, upper $95 \%$ confidence limit of diabetic control group $(0 \%$ correction). Data are mean \pm SEM. Statistics: motor conduction velocity, correction was significant for all doses $5,15,500$ $\mathrm{mg} \cdot \mathrm{kg}^{-1} \cdot \mathrm{day}^{-1}, \quad p<0.05 ; 50 \mathrm{mg} \cdot \mathrm{kg}^{-1} \cdot \mathrm{day}^{-1}, \quad p<0.01 ; 150$ $\mathrm{mg} \cdot \mathrm{kg}^{-1} \cdot \mathrm{day}^{-1}, p<0.001$; although correction was incomplete for all doses $(p<0.001)$. Sensory conduction velocity, correction was significant for all doses $5,500 \mathrm{mg}$. $\mathrm{kg}^{-1} \cdot \mathrm{day}^{-1}, p<0.05 ; 15 \mathrm{mg} \cdot \mathrm{kg}^{-1} \cdot \mathrm{day}^{-1}, p<0.01 ; 50,150$ $\mathrm{mg} \cdot \mathrm{kg}^{-1} \cdot$ day $^{-1}, p<0.001$; although correction was incomplete for all doses $(p<0.001)$

NCV reduction was limited to $6.4 \pm 0.5 \%(p<0.001)$ although prevention remained incomplete compared to non-diabetic controls $(p<0.001)$. Combined treatment with vitamin $\mathrm{C}$ and the lower dose of vitamin $\mathrm{E}$ gave a greater degree of protection than either component alone $(p<0.001)$. The resultant NCV value matched that for the high dose of vitamin $E$, although a significant deficit remained $(6.5 \pm 0.5 \%, p<0.001)$ compared to the non-diabetic group. The combination gave results consistent with a simple addition of anti-oxidant effects. Thus, the $35.4 \%$ protection by vitamin $C$ superimposed on the $38.8 \%$ protection provided by vitamin $E$ would theoretically lead to an NCV value of $58.9 \mathrm{~m} \cdot \mathrm{s}^{-1}$ compared to the observed value of $59.6 \pm 0.3 \mathrm{~m} \cdot \mathrm{s}^{-1}$, which did not differ significantly.

Sensory saphenous NCV (Fig. 1B) was reduced by $16.6 \pm 1.2 \%(p<0.001)$ after 1 month of diabetes. Vitamin $\mathrm{C}$ treatment provided partial protection $(8.4 \pm 0.5 \%$ deficit, $p<0.001$ vs non-diabetic and untreated diabetic groups). With vitamin $\mathrm{E}$, there was a dose-dependent prevention of sensory NCV deficits $(p<0.001)$, values for the lower-dose remaining depressed compared to the non-diabetic group $(p<0.01)$ whereas for the high dose they fell within

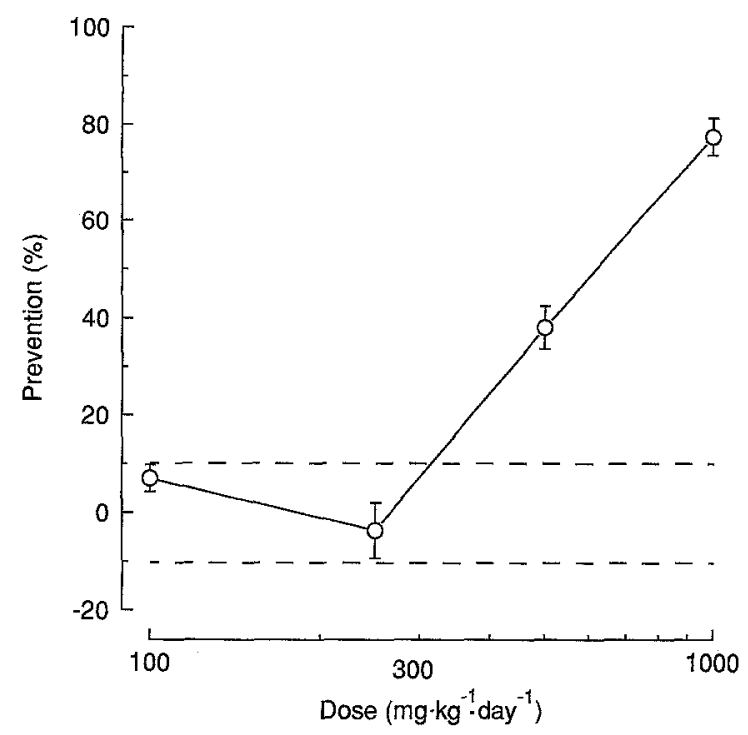

Fig.3. Dose-response relationship for prevention of sciatic motor conduction velocity deficits by vitamin $E$ treatment. Doses were $100,250,500$ and $1000 \mathrm{mg} \cdot \mathrm{kg}^{-1} \cdot$ day $^{-1}$ (group $n=6-10)$. Horizontal dashed lines, $95 \%$ confidence limits of diabetic control group ( $0 \%$ prevention). Data are mean \pm SEM Statistics, conduction velocity was increased for 500 and $1000 \mathrm{mg} \cdot \mathrm{kg}^{-1} \cdot$ day $^{-1}$ doses $(p<0.001)$, although prevention of the deficit was incomplete $(p<0.001)$

the non-diabetic range. Combined vitamin $\mathrm{C}$ and low-dose vitamin $\mathrm{E}$ treatment gave the highest sensory NCV which was not significantly different from the non-diabetic group. As with motor NCV, the joint treatment effect on sensory NCV was comparable to expectations based on additivity of anti-oxidant potential. Thus, the 47.0 and $68.1 \%$, protection afforded by vitamins $\mathrm{C}$ and $\mathrm{E}$ respectively combine to give a predicted sensory NCV of $60.0 \mathrm{~m} \cdot \mathrm{s}^{-1}$ which is in good agreement with the observed value of $60.7 \pm 0.5 \mathrm{~m} \cdot \mathrm{s}^{-1}$.

Under hypoxic conditions, in vitro, there was a markedly prolonged decline of sciatic nerve compound action potential amplitude with diabetes, which was true for all groups regardless of treatment. Thus, the duration of hypoxia necessary for an $80 \%$ amplitude reduction was elevated from $20.4 \pm 0.9 \mathrm{~min}$ in the non-diabetic group to $35.1 \pm 1.0 \mathrm{~min}$ in the untreated diabetic group $(p<0.001)$. This was not significantly altered by vitamin $\mathrm{C}$ or vitamin $\mathrm{E}$ treatments alone. For the joint vitamin $\mathrm{C}$ and $\mathrm{E}$ treated group, $80 \%$ conduction failure was achieved in $31.8 \pm 1.1 \mathrm{~min}$ which was less $(p<0.05)$ than for untreated diabetes while remaining markedly elevated compared to the non-diabetic group $(p<0.001)$. Within the treated and untreated diabetic groups there was a modest but statistically significant negative correlation between sciatic motor NCV as the dependent variable and $80 \%$ conduction failure time as the independent variable $(r=$ $-0.363, p=0.023$ ). 

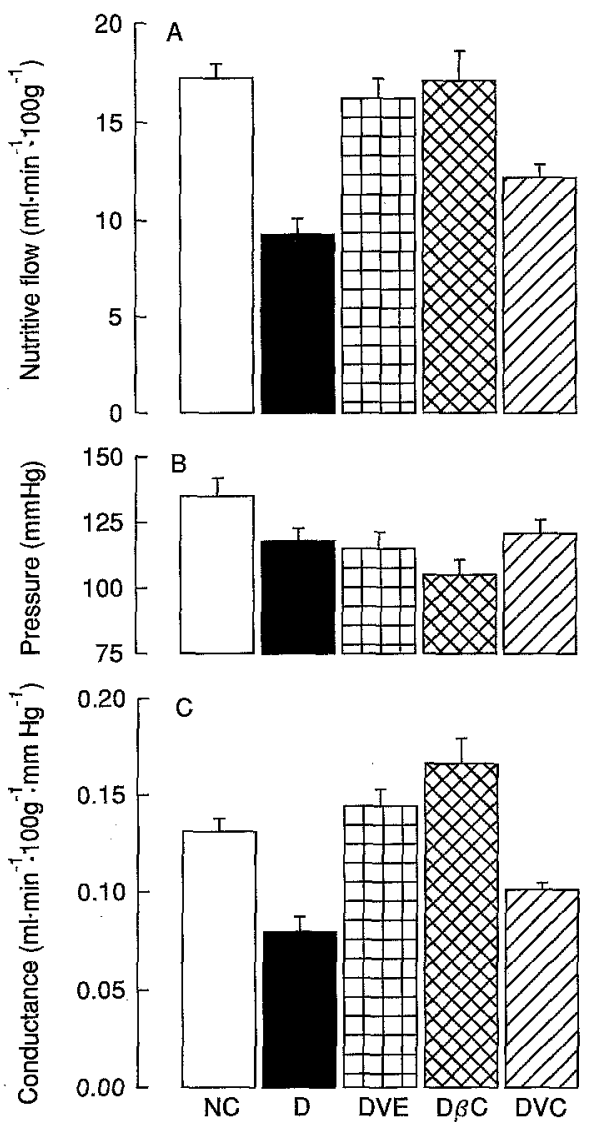

Fig. $4 \mathbf{A}-\mathrm{C}$. Effects of diabetes and $\beta$-carotene, vitamin $\mathrm{C}$ and vitamin $E$ treatments on sciatic nutritive endoneurial blood flow (A), mean systemic blood pressure (B) and endoneurial vascular conductance $(\mathbf{C})$. NC, Non-diabetic control group $(n=10)$; D, 1 month diabetic group $(n=10)$; DVE, 1 month diabetic group treated with vitamin $\mathrm{E}\left(1000 \mathrm{mg} \cdot \mathrm{kg}^{-1} \cdot \mathrm{day}^{-1}\right)$ from induction $(n=9) ; \mathrm{D} \beta \mathrm{C}, 1$ month diabetic group treated with $\beta$-carotene $\left(1000 \mathrm{mg} \cdot \mathrm{kg}^{-1} \cdot \mathrm{day}^{-1}\right)$ from induction $(n=11)$; DVC, 1 month diabetic group treated with vitamin $\mathrm{C}$ $\left(150 \mathrm{mg} \cdot \mathrm{kg}^{-1} \cdot \mathrm{day}^{-1}\right)$ from induction $(n=12)$. Data are mean \pm SEM Statistics: flow, NC vs D, $p<0.001$; NC vs DVC, $p<0.01$; NC vs D $\beta C$, DVE, NS; D vs D $\beta C$, DVE, $p<0.001$; D vs DVC, $p<0.01$. Blood pressure, $\mathrm{NC}$ vs $\mathrm{D} \beta \mathrm{C}, p<0.01$; all other comparisons NS. Conductance, NC vs D, $p<0.001 ; \mathrm{NC}$ vs DVC, $p<0.05$; NC vs DVE, NS; NC vs D $\beta C, p<0.05 ; \mathrm{D}$ vs DVC, $p<0.01 ; \mathrm{D}$ vs $\mathrm{D} \beta \mathrm{C}, \mathrm{DVE}, p<0.001$

The dose-response curves for vitamin $\mathrm{C}$ reversal of deficits in motor NCV to tibialis anterior muscle and sensory saphenous NCV are shown in Figure 2. The highest degree of reversal was found with $50-150$ $\mathrm{mg} \cdot \mathrm{kg}^{-1} \cdot$ day $^{-1}$ treatment, approximately $35 \%$ for motor and $45 \%$ for sensory NCV $(p<0.001)$, similar to the level of protection afforded over the first month of diabetes (Fig. 1). At the highest dose examined $\left(500 \mathrm{mg} \cdot \mathrm{kg}^{-1} \cdot\right.$ day $\left.^{-1}\right)$ there was a tendency for NCV to be reduced compared to intermediate doses, which was statistically significant for saphenous NCV $(p=0.0012$, Mann-Whitney U-test, 150 $\mathrm{mg} \cdot \mathrm{kg}^{-1} \cdot \mathrm{day}^{-1}$ vs $\left.500 \mathrm{mg} \cdot \mathrm{kg}^{-1} \cdot \mathrm{day}^{-1}\right)$. Figure 3 shows the dose-response curve for vitamin $\mathrm{E}$ prevention of motor NCV deficits. Maximum protection

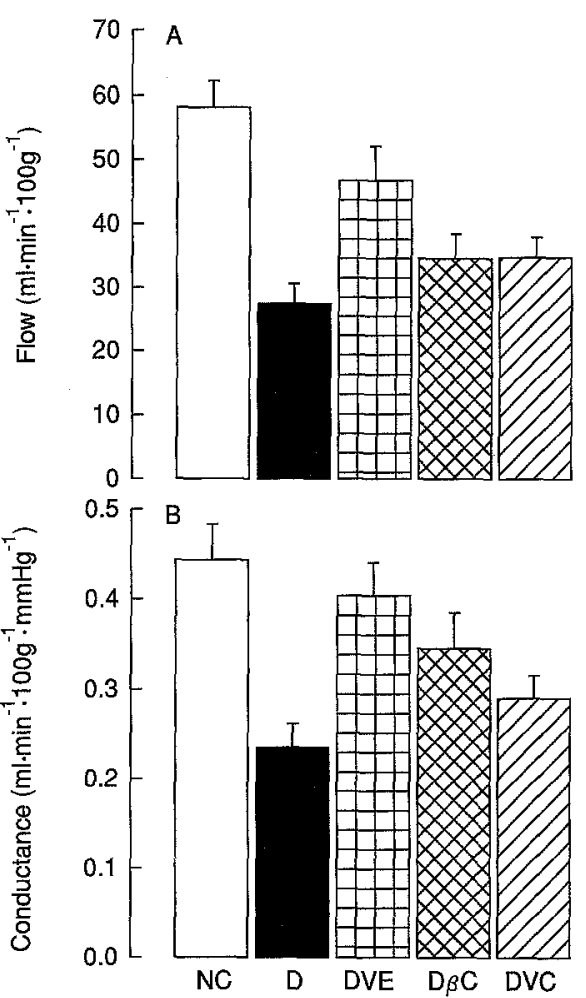

Fig.5A, B. Effects of diabetes and $\beta$-carotene, vitamin $\mathrm{C}$ and vitamin $\mathrm{E}$ treatments on sciatic composite endoneurial blood flow (A) and composite vascular conductance (B). NC, Nondiabetic control group $(n=10) ; \mathrm{D}, 1$ month diabetic group $(n=10)$; DVE, 1 month diabetic group treated with vitamin $\mathrm{E}$ $\left(1000 \mathrm{mg} \cdot \mathrm{kg}^{-1} \cdot\right.$ day $\left.^{-1}\right)$ from induction $(n=9)$; D BC, 1 month diabetic group treated with $\beta$-carotene $\left(1000 \mathrm{mg} \cdot \mathrm{kg}^{-1} \cdot\right.$ day $\left.^{-1}\right)$ from induction $(n=11)$; DVC, 1 month diabetic group treated with vitamin $\mathrm{C}\left(150 \mathrm{mg} \cdot \mathrm{kg}^{-1} \cdot \mathrm{day}^{-1}\right)$ from induction $(n=12)$. Data are mean $\pm S E M$ Statistics: composite flow, NC vs D, DVC, D $\beta C, p<0.001$; NC vs DVE, NS; D vs DVC, D $\beta C$, NS; $\mathrm{D}$ vs DVE, $p<0.01$. Conductance, NC vs $\mathrm{D}, p<0.001 ; \mathrm{NC}$ vs DVC, $p<0.05 ; N C$ vs D $\beta C, D V E, N S ; D$ vs DVE, $p<0.01 ; \mathrm{D}$ vs D $\beta C$, DVC, NS

(approximately $80 \%$ ) was obtained with the highest dose used $\left(1000 \mathrm{mg} \cdot \mathrm{kg}^{-1} \cdot\right.$ day $\left.^{-1}\right)$ and doses less than $500 \mathrm{mg} \cdot \mathrm{kg}^{-1} \cdot \mathrm{day}^{-1}$ had a negligible effect on motor NCV.

Study 2: effects of vitamins $C, E$ and $\beta$-carotene on sciatic nerve blood flow and motor conduction velocity. Motor NCVs for vitamins C $\left(55.9 \pm 0.4 \mathrm{~m} \cdot \mathrm{s}^{-1}\right.$, $n=12)$ and $\mathrm{E}\left(62.2 \pm 0.6 \mathrm{~m} \cdot \mathrm{s}^{-1}, n=9\right)$ treatments were elevated $(p<0.001)$ compared to untreated diabetes $\left(51.2 \pm 0.6 \mathrm{~m} \cdot \mathrm{s}^{-1}, n=10\right)$, but remained reduced $(p<0.001$ for vitamin $\mathrm{C}, p<0.05$ for vitamin E) compared to the non-diabetic group $(64.1 \pm 0.4$ $\mathrm{m} \cdot \mathrm{s}^{-1}, n=10$ ), in agreement with data from the first study. The greatest protection $(90.1 \pm 3.7 \%$, $p<0.001)$ was given by $\beta$-carotene treatment; NCV $\left(62.8 \pm 0.5 \mathrm{~m} \cdot \mathrm{s}^{-1}, n=11\right)$ was not significantly different from the non-diabetic group.

Endoneurial nutritive blood flow (Fig. 4A) was $46.1 \pm 4.6 \%$ reduced by 1 month of diabetes 
$(p<0.001)$. Treatment during this period prevented the deficit to the extent of $86.8 \pm 12.4 \%(p<0.001$, vitamin E), $98.0 \pm 18.8 \%(p<0.001, \beta$-carotene $)$ and $36.3 \pm 8.0 \%(p<0.01$, vitamin $C)$. In the latter case, flow remained significantly reduced compared to the non-diabetic group $(p<0.01)$. Mean systemic blood pressure (Fig. 4B) tended to be reduced by diabetes, by an average of approximately $15 \%$, although this only reached statistical significance $(p<0.01)$ for $\beta$ carotene treatment. As peripheral nerve vascular supply has minimal autoregulatory responses to changes in blood pressure [29], this would tend to exacerbate diabetic effects and minimize treatment effects on vasa nervorum. Blood pressure differences are taken into account when the data are expressed as vascular conductance (Fig. 4C). The diabetic conductance deficit was $39.2 \pm 5.8 \%(p<0.001)$. Conductance tended to be supranormal in the vitamin $E$ and $\beta$-carotene treated groups, and this was statistically significant in the latter case $(p<0.05)$. Vitamin $C$ treatment improved conductance by $27.1 \pm 4.1 \%$ $(p<0.01)$, however it remained $22.7 \pm 2.5 \%$ $(p<0.05)$ lower than the non-diabetic group.

Hydrogen clearance curves for peripheral nerve are generally composed of two components. A fast component arises due to clearance by large vessels (arterial, venous and arterio-venous flow) and is non-nutritive while a slow component represents capillary (nutritive) clearance $[23,24]$. The composite value for both components gives an index of total (nutritive plus non-nutritive) endoneurial flow. Composite flow was reduced by $52.8 \pm 5.2 \%(p<0.001)$ after 1 month of diabetes (Fig. 5A). This was partially prevented by vitamin $\mathrm{E}(62.7 \pm 17.6 \%$ protection, $p<0.01$ ) whereas $\beta$-carotene and vitamin $C$ had lesser effects which were not statistically significant compared to the untreated diabetic group, composite flow remaining reduced compared to the non-diabetic group $(p<0.001)$. When corrected for blood pressure differences, composite conductance (Fig. 5B) was depressed by diabetes $(46.9 \pm 6.0 \%$, $p<0.001)$ and in the vitamin C-treated group $(34.5 \pm 5.7 \%, p<0.05)$. For vitamin $\mathrm{E}$, conductance was elevated compared to untreated diabetes $(p<0.01)$, and was not significantly different from the value for the non-diabetic group. With $\beta$-carotene treatment, conductance was not significantly different from diabetic or non-diabetic groups. There was a correlation between NCV (dependent variable) and nutritive blood flow (independent variable) for the treated diabetic rats $(r=0.457$, $p=0.015$ ), but no significant correlation was found between NCV and composite flow $(r=0.004$, $p=0.983$ ).

\section{Discussion}

The data show that some natural anti-oxidants available in the diet can protect against the development of NCV and nutritive endoneurial blood flow deficits in experimental diabetes. This finding is in agreement with other intervention studies using free radical scavengers; NCV deficits were prevented by butylated hydroxytoluene [12] partially prevented but not corrected by glutathione [13] and both prevented and corrected by probucol [11]. In addition, probucol halted the development of reduced nutritive blood flow and endoneurial hypoxia [11]. The degree of NCV protection by vitamins $C$ and $E$ was greater for saphenous sensory than sciatic motor fibres, as noted for other treatments such as aldose reductase inhibition [30].

The effects of vitamin $C, E$ and $\beta$-carotene were not equivalent, even taking dose differences into account. In particular, vitamin $C$ provided fairly poor neuroprotection. One possible explanation may be that lipophilic scavengers, such as vitamin $E$ or $\beta$-carotene, are more effective than hydrophilic species, presumably because they may be present at high concentrations in cell membranes subjected to ROS attack. This argument may be compatible with the partial prevention and a lack of reversal of NCV deficits by the hydrophilic anti-oxidant, glutathione [13]. However, in preliminary experiments we have noted that the glutathione precursor, $\mathrm{N}$-acetyl-L-cysteine provides a very high level of protection against NCV and blood flow defects in our model [31], therefore, this view is unlikely to be correct. Another possible explanation relates to cellular uptake of vitamin $C$, which is reduced by both hyperglycaemia and hypoinsulinaemia [32]; an effect that might limit access to important intracellular sites of action. Vitamin $C$ has been suggested to act via regeneration of $\alpha$-tocopherol from the tocopheroxyl radical formed when vitamin $E$ reacts with ROS [33]. However, it is not clear whether this effect, observed in vitro, also operates in vivo [34]. The NCV and blood flow data indirectly suggest that vitamin $\mathrm{E}$ regeneration is not a major action, as there was a large discrepancy between vitamin $C$ and $E$ effects. Diabetic rats, even without treatment, have a greater than normal vitamin $\mathrm{E}$ consumption because they are hyperphagic. This is reflected in tissue levels, including sciatic nerve where they are approximately doubled [15]. The dose of vitamin $E$ needed to partially prevent NCV deficits was at least 100 times greater than the rats' usual dietary intake. Thus, even if vitamin $\mathrm{C}$ had efficiently regenerated all the available vitamin $E$ that the rats normally consumed, there would still not have been enough to influence NCV, judging from the vitamin $\mathrm{E}$ dose-response curve. There was also little indication that vitamin $\mathrm{E}$ overwhelmed the action of vitamin $C$ in the joint treatment group. In- 
stead effects of the two scavengers were additive for motor and sensory NCV, as if they were acting by independent complementary mechanisms or at different sites. This interaction appears to be relatively simple compared to joint treatment experiments using aldose reductase inhibitors and $\omega-6$ essential fatty acids where marked facilitatory effects have been observed [35]. Thus, vitamin $\mathrm{C}$ is likely to function as an anti-oxidant in its own right, presumably scavenging ROS in an aqueous environment, either in the circulation or intracellularly. The limited effect of vitamin C on NCV and blood flow, compared to other hydrophilic scavengers such as $\mathrm{N}$-acetyl-L-cysteine [31], could be due to its other role as a pro-oxidant in generating ROS by the process of auto-oxidation [17]. A dual anti-/pro-oxidant action may also explain the shape of the vitamin $\mathrm{C}$ dose-response curve, where the highest dose was less effective than intermediate doses against NCV deficits.

A previous study [15] showed that rearing diabetic rats on a vitamin E-deficient diet exacerbated increases in markers of oxidative stress (conjugated dienes and hydroperoxides) in neural tissues, the reduction in sciatic nerve glutatione content, and NCV deficits. However, the converse experiment, using a vitamin E-enriched diet, did not significantly alter conjugated dienes and hydroperoxides, reduced glutatione and NCV. The latter finding contrasts with the present data, although the lack of effect of vitamin $E$ was likely to be because of the relatively low dose used $\left(190 \mathrm{mg} \cdot \mathrm{kg}^{-1} 3\right.$ times per week, or $109 \mathrm{mg}$. $\mathrm{kg}^{-1} \cdot$ day $^{-1}$ ) in that study. Thus, the dose-response curve (Fig.3) shows that little functional effect would be expected for doses of vitamin $\mathrm{E}$ below 250 $\mathrm{mg} \cdot \mathrm{kg}^{-1} \cdot$ day $^{-1}$. Presumably this would also be true for markers of oxidative stress and glutathione. It must be noted, however, that the short-term effects of anti-oxidant treatment appear to be primarily neurovascular, therefore, if technically feasible, measurement of these parameters in vasa nervorum rather than axons and Schwann cells would be of greater relevance.

Treatment with $\beta$-carotene was at least as successful as vitamin $E$ against NCV and nutritive blood flow abnormalities. As $\beta$-carotene is not a chainbreaking anti-oxidant in the manner of vitamin $\mathrm{E}$, but is more effective against excited singlet oxygen species [18], this may suggest that more than one type of ROS is important for diabetic neural and neurovascular deficits. The degree of protection against nutritive blood flow deficits was roughly in line with effects on NCV for $\beta$-carotene and vitamins $C$ and E. However, there was no correlation between NCV and composite flow. One reason why changes in composite flow may not correlate with NCV when using data pooled from different treatments is because they alter the pattern of endoneurial flow in different ways. Thus, $\beta$-carotene had a greater effect on nu- tritive ( $84 \%$ increase) than composite ( $29 \%$ increase) flow ( $p=0.0098$, Wilcoxon signed rank test) whereas vitamin $\mathrm{E}$ caused similar increases of approximately $70 \%$ for both measures. This suggests that $\beta$-carotene had a more specific action favouring capillary flow, whereas vitamin $\mathrm{E}$ promoted a generalized flow increase in both large and small vessels. Other examples of flow pattern changes have been documented. Aldose reductase inhibitors and N-acetyl-L-cysteine caused diversion of blood from arterio-venous shunts to the endoneurial capillary bed $[30,31]$, whereas for high-dose insulin, arterio-venous shunting increased to an extent that compromised nutritive flow, the result being endoneurial hypoxia in the absence of any reduction in composite flow [36]. Given the potential for treatments to alter the pattern of nerve perfusion, it is important to measure flow in the endoneurial capillary bed rather than relying on more general whole nerve flow estimates when assessing the potential mechanisms of action of pharmacological agents against NCV abnormalities. Thus, an increase in whole nerve laser-Doppler flux with vitamin $\mathrm{E}$ treatment has recently been reported [37], in line with the hydrogen clearance measurements, however, it is unlikely that the laser-Doppler method would detect the more complex changes in endoneurial flow for agents such as $\beta$-carotene.

The mechanisms underlying the decreased flow in diabetes, and the effects of free radical scavenger treatment, are not known in detail. However, it has been hypothesized that alterations in vascular endothelium result in a deficit in the production/release/ action of prostacyclin and NO as well as elevated synthesis of angiotensin II and endothelin 1 [6, 8, 38-40]. Thus, a "push-pull" system of reduced local vasodilation and increased vasoconstriction may operate to decrease blood flow. Diabetic NCV abnormalities can be mimicked in non-diabetic rats by joint cyclooxygenase/NO synthase inhibition [10]. Vitamin E treatment corrected an abnormal prostacyclin/thromboxane $A_{2}$ ratio in diabetic rats [4]. Agents such as evening primrose oil, which increase vasa nervorum prostacyclin synthesis [41], also prevent NCV abnormalities, nutritive blood flow deficits, and endoneurial hypoxia [42]. Thus, one action of vitamin $E$, and perhaps other anti-oxidants, could be to prevent decreased vasa nervorum prostacyclin synthesis. Acute treatment with free radical scavengers improves in vitro endothelial NO release for large vessels from diabetic rats [43, 44], and chronic treatment prevents the development of impaired endothelium-dependent relaxation (Archibald V, Cotter MA, Cameron NE, unpublished observations). Superoxide radicals neutralize NO, a reaction producing hydroxyl radicals that could damage the endothelium [45, 46]. Thus, it is plausible that anti-oxidants both protect vasa nervorum NO output and prevent endothelial damage. More widespread effects are also indicated; probucol 
treatment of diabetic rats prevented the elevation of plasma angiotensin converting enzyme concentration, a marker of both endothelial damage and increased activity in the local renin-angiotensin system [11].

Vitamin $\mathrm{E}$ and $\mathrm{C}$ effects on resistance to hypoxic conduction failure were considerably smaller than for NCV. Hypoxic resistance reflects an adaptation to the hypoxic endoneurium, involving increased reliance on anaerobic energy metabolism $[6,24]$. It also occurs in non-diabetic rats reared under hypoxic conditions or with chronic manipulations which reduce nerve blood flow $[10,47]$. Vitamins $\mathrm{E}$ and $\mathrm{C}$-mediated increases in nerve perfusion would partially reduce endoneurial hypoxia, however, this may not be sufficient to prevent hypoxic resistance, which is substantially less amenable than NCV to treatments that elevate blood flow [6]. In addition, hyperglycaemic exposure can independently stimulate nerve anaerobic metabolism [48]. Nerve function could also be adversely affected by "hyperglycaemic pseudohypoxia" caused by excessive flux through the second half of the polyol pathway which may promote an elevation in cell NADH/NAD ratio with widespread effects on intermediate metabolism [49]. However, it is unlikely that this putative mechanism can explain resistance to hypoxic conduction failure which is largely prevented in diabetic rats by using peripheral vasodilator or evening primrose oil treatments which cause greater increases in nerve perfusion $[6,21,39,42]$ than the anti-oxidants used in this study. In addition, partial reversal of hypoxic resistance was noted after 7 days of chronic electrical nerve stimulation [50]. These manipulations do not alter the level of hyperglycaemia or polyol pathway metabolism, therefore hypoxic resistance can be markedly reduced despite the presence of a diabetic level of hyperglycaemic pseudohypoxia. In addition, hypoxic resistance is a feature of experimental galactosaemia where flux is limited to the first half of the polyol pathway $[24,51]$ and pseudohypoxia would not be expected. The presence of hypoxic resistance in anti-oxidant-treated diabetic rats in this study is, therefore, consistent with an incomplete prevention of nerve perfusion and NCV deficits. A previous investigation using butylated hydroxytoluene, which gave better preservation of NCV than vitamins $\mathrm{C}$ or $\mathrm{E}$, also showed a greater effect against hypoxic resistance [12].

Direct and indirect evidence shows that diabetic patients with neuropathy have reduced nerve blood flow and endoneurial hypoxia [52-54]. Thus, free radical scavenger treatment might theoretically be suitable. One rather disappointing finding is that pharmacological rather than physiological concentrations of natural anti-oxidants are necessary to protect neurovascular function in diabetic rats. This may in part be due to the high levels of hyperglycaemia in experimental diabetes. The processes of advanced glycation and glucose auto-oxidation are thought to be important sources of ROS [17], therefore, free radical generation is likely to be greater in experimental models than in patients with relatively well-controlled diabetes. Thus, anti-oxidants may be effective at lower doses in patients and the magnitude of general cardiovascular effects of acute treatment [5] encourages the view that this therapeutic approach merits examination in clinical trials against neuropathy.

Acknowledgements. N.E. C. is supported by a Wellcome Trust Research Leave Fellowship. A. L. is funded by the British Diabetic Association and K.C.D. was in receipt of a Scotia Pharmaceuticals research studentship.

\section{References}

1. Ceriello A, Guigliano D, Quatraro A, Lefebvre PJ (1991) Metabolic control may influence the increased superoxide anion production in the diabetic serum. Diabetic Med 8: $540-542$

2. Loven DH, Schedl H, Wilson H et al. (1986) Effects of insulin and oral glutathione on glutathione levels and superoxide dismutase activities in organs of rats with streptozotocin-induced diabetes. Diabetes 35: 503-507

3. Wohaieb SA, Godin DV (1987) Alterations in free radical tissue-defense mechanisms in streptozotocin-induced diabetes in rats. Effects of insulin treatment. Diabetes 36: 1014-1018

4. Karpen CW, Pritchard KA, Arnold JH, Cornwell DG, Pangonamala RV (1982) Restoration of the prostacyclin/ thromboxane $\mathrm{A}_{2}$ balance in the diabetic rat: influence of vitamin E. Diabetes 31: 947-951

5. Ceriello A, Guigliano D, Quatraro A, Lefebvre PJ (1991) Anti-oxidants show an anti-hypertensive effect in diabetic and hypertensive subjects. Clin Sci 81: 739-742

6. Cameron NE, Cotter MA (1994) The relationship of vascular changes to metabolic factors in diabetes mellitus and their role in the development of peripheral nerve complications. Diabetes Metab Rev 10: 189-224

7. Pieper GM, Gross GJ (1988) Oxygen free radicals abolish endothelium-dependent relaxation in diabetic rat aorta. Am J Physiol 255:H825-H833

8. Cameron NE, Cotter MA (1992) Impaired contraction and relaxation in aorta from streptozotocin-diabetic rats: role of polyol pathway activity. Diabetologia 35: 1011-1019

9. Cohen RA (1993) Dysfunction of vascular endothelium in diabetes mellitus. Circulation 87 [Suppl V]:V67-V76

10. Cameron NE, Cotter MA, Dines KC, Maxfield EK (1993) Pharmacological manipulation of vascular endothelium in non-diabetic and streptozotocin-diabetic rats: effects on nerve conduction, hypoxic resistance and endoneurial capillarization. Diabetologia 36: 516-522

11. Cameron NE, Cotter MA, Archibald V, Dines KC, Maxfield EK (1994) Anti-oxidant and pro-oxidant effects on nerve conduction velocity, endoneurial blood flow and oxygen tension in non-diabetic and streptozotocin-diabetic rats. Diabetologia 37: 449-459

12. Cameron NE, Cotter MA, Maxfield EK (1993) Antioxidant treatment prevents the development of peripheral nerve dysfunction in streptozotocin-diabetic rats. Diabetologia 36: 299-304

13. Bravenboer B, Kapelle AC, Hamers FPT, van Buren T, Erkelens DW, Gispen WH (1992) Potential use of glutathione 
for the prevention and treatment of diabetic neuropathy in the streptozotocin-induced diabetic rat. Diabetologia 35 : 813-817

14. McLennan S, Yue DK, Fisher E, Capogreco C, Heffernan S, Ross GR, Turtle JR (1988) Deficiency of ascorbic acid in experimental diabetes: relationship with collagen and polyol pathway abnormalities. Diabetes 37: 359-361

15. Nickander KK, Schmelzer JD, Rohwer DA, Low PA (1994) Effects of $\alpha$-tocopherol deficiency on indices of oxidative stress in normal and diabetic peripheral nerve. J Neurol Sci 126: 6-14

16. Young IS, Torney JJ, Trimble ER (1992) The effect of ascorbate supplementation on oxidative stress in the streptozotocin diabetic rat. Free Rad Biol Med 13: 41-46

17. Wolff SP (1993) Diabetes mellitus and free radicals. $\mathrm{Br}$ Med Bull 49: 642-652

18. Nohl H (1993) Involvement of free radicals in ageing: a consequence or cause of senescence. Br Med Bull 49: 653667

19. Cheeseman KH, Slater TF (1993) An introduction to free radical biochemistry. Br Med Bull 49: 481-493

20. Cameron NE, Cotter MA, Robertson S (1989) The effect of aldose reductase inhibition on the pattern of nerve conduction deficits in diabetic rats. Q J Exp Physiol 74: 917926

21. Cameron NE, Cotter MA, Robertson S (1991) Effects of essential fatty acid dietary supplementation on peripheral nerve and skeletal muscle function and capillarization in streptozocin diabetic rats. Diabetes 40: 532-539

22. Cameron NE, Cotter MA, Low PA (1991) Nerve blood flow in early experimental diabetes in rats: relation to conduction deficits. Am J Physiol 261:E1-E8

23. Day TJ, Lagerlund TD, Low PA (1989) Analysis of $\mathbf{H}_{2}$ clearance curves used to measure blood flow in rat sciatic nerve. J Physiol 414: 35-54

24. Low PA, Lagerlund TD, McManis PG (1989) Nerve blood flow and oxygen delivery in normal, diabetic and ischemic neuropathy. Int Rev Neurobiol 31: 355-438

25. Tilton RG, Chang K, Pugliese G et al. (1989) Prevention of hemodynamic and vascular albumin filtration changes in diabetic rats by aldose reductase inhibitors. Diabetes 37 : 1258-1270

26. Heyman MA, Payne BD, Hoffman JIE, Rudolf AM (1977) Blood flow measurements with radionuclide-labelled particles. Prog Cardiovasc Dis 20: 55-79

27. Hassan K, Santiago J, Williamson J (1993) Acute hyperglycemia-induced increases in regional blood flow are prevented by pyruvate and tolrestat. Diabetes [Suppl 1]:189A (Abstract)

28. Kihara M, Zollman PJ, Smithson IL, Lagerlund TD, Low PA (1994) Hypoxic effect of exogenous insulin on normal and diabetic peripheral nerve. Am J Physiol 266:E980E985

29. Low PA, Tuck RR (1984) Effects of changes in blood pressure, respiratory acidosis and hypoxia on blood flow in the sciatic nerve of the rat. J Physiol 347: 513-524

30. Cameron NE, Cotter MA, Dines KC, Maxfield EK, Carey F, Mirrlees DJ (1994) Aldose reductase inhibition, nerve perfusion, oxygenation and function in streptozotocin-diabetic rats: dose-response considerations and independence from a myo-inositol mechanism. Diabetologia 37: $651-663$

31. Cameron NE, Cotter MA (1995) Comparison of the effects of chronic aldose reductase inhibitor and acetyl-L-cysteine treatments on peripheral nerve blood flow and function in anaesthetized diabetic rats. J Physiol 483P:142P-143P (Abstract)
32. Kapeghian JC, Verlangieri AJ (1984) The effects of glucose on ascorbic acid uptake in heart endothelial cells: possible pathogenesis of diabetic angiopathies. Life Sci 34: 577-584

33. Packer JE, Slater TF, Wilson RL (1979) Direct observation of a free radical interaction between vitamin $E$ and vitamin C. Nature 278: 737-738

34. Burton GW, Wronska U, Stone L, Foster DO, Ingold KU (1990) Biokinetics of RRR- $\alpha$-tocopherol in the male guinea pig at three dietary levels of vitamin $C$ and two levels of vitamin E. Evidence that vitamin C does not 'spare' vitamin $E$ in vivo. Lipids 25: $199-210$

35. Cotter MA, Cameron NE, Dines KC (1995) Facilitation between the effects of polyol pathway inhibition and $\omega-6$ essential fatty acid treatment on peripheral nerve function and blood flow in anaesthetized diabetic rats. J Physiol 483P:141P-142P (Abstract)

36. Kihara M, Zollman PJ, Smithson IL, Lagerlund TD, Low PA (1994) Hypoxic effect of exogenous insulin on normal and diabetic peripheral nerve. Am J Physiol 266:E980E985

37. Karasu C, Dewhurst M, Stevens EJ, Tomlinson DR (1995) Effects of anti-oxidant treatment on sciatic nerve dysfunction in streptozotocin-diabetic rats; comparison with essential fatty acids. Diabetologia 38: 129-134

38. Ward KK, Low PA, Schmelzer JD, Zochodne DW (1989) Prostacyclin and noradrenaline in peripheral nerve of chronic experimental diabetes in rats. Brain 112: 197-208

39. Maxfield EK, Cameron NE, Cotter MA, Dines KC (1993) Angiotensin II receptor blockade improves nerve function, modulates nerve blood flow and stimulates endoneurial angiogenesis in streptozotocin-diabetic rats. Diabetologia 36: 1230-1237

40. Cameron NE, Dines KC, Cotter MA (1994) The potential contribution of endothelin-1 to neurovascular abnormalities in streptozotocin-diabetic rats. Diabetologia 37: 12091215

41. Stevens EJ, Carrington AL, Tomlinson DR (1993) Prostacyclin release in experimental diabetes: effects of evening primrose oil. Prostaglandins Leukot Essent Fatty Acids 49: 699-706

42. Cameron NE, Cotter MA (1994) Effects of evening primrose oil treatment on sciatic nerve blood flow and endoneurial oxygen tension in streptozotocin-diabetic rats. Acta Diabetologica 31: 220-225

43. Langenstroer P, Pieper GM (1992) Regulation of spontaneous EDRF release in diabetic rat aorta by oxygen free radicals. Am J Physiol 263:H257-H265

44. Pieper GM, Mei DA, Langenstroer P, O'Rourke ST (1992) Bioassay of endothelium-derived relaxing factor in diabetic rat aorta. Am J Physiol 263:H676-H680

45. Beckman JS, Beckman TW, Chen J, Marshall PA, Freeman BA (1990) Apparent hydroxyl radical production by peroxynitrite: implications for endothelial injury from nitric oxide and superoxide. Proc Natl Acad Sci USA 87: 16201624

46. Pieper GM, Langenstroer P, Gross GJ (1993) Hydroxyl radicals mediate injury to endothelium-dependent relaxation in diabetic rats. Mol Cell Biochem 122: 139-145

47. Low PA, Schmelzer JD, Ward KK, Yao JK (1986) Experimental chronic hypoxic neuropathy: relevance to diabetic neuropathy. Am J Physiol 250:E94-E99

48. Strupp M, Jund R, Schneider U, Grafe P (1991) Glucose availability and sensitivity to anoxia of isolated rat peroneal nerve. Am J Physiol 261:E389-E394

49. Williamson JR, Chang K, Frangos M et al. (1993) Hyperglycemic pseudohypoxia and diabetic complications. Diabetes 42 : 801-813 
50. Cameron NE, Cotter MA, Robertson S, Maxfield EK (1993) Nerve function in experimental diabetes in rats: effects of electrical activation. Am J Physiol 264:E161-E166

51 Cameron NE, Cotter MA, Robertson S, Cox D (1992) Muscle and nerve dysfunction in rats with experimental galactosaemia. Exp Physiol 77: 89-108

52. Tesfaye S, Malik R, Ward JD (1994) Vascular factors in diabetic neuropathy. Diabetologia 37: 847-854
53. Tesfaye S, Harris N, Jakubowski JJ et al. (1993) Impaired blood flow and arterio-venous shunting in human diabetic neuropathy: a novel technique of nerve photography and fluorescein angiography. Diabetologia 36: 1266-1274

54. Newrick PG, Wilson AJ, Jakubowski J, Boulton AJM, Ward JD (1986) Sural nerve oxygen tension in diabetes. B M J 293: $1053-1054$ 